\title{
Comparative Study between Poly(ethylene-co-vinyl acetate) - EVA Expanded Composites Filled with Banana Fiber and Wood Flour
}

\author{
Matheus Vinicius Gregory Zimmermann ${ }^{a *}$, Taís Turella ${ }^{a}$, \\ Ruth Marlene Campomanes Santana ${ }^{b}$, Ademir José Zattera ${ }^{a}$ \\ ${ }^{a}$ Postgraduate Program in Process and Technology Engineering - PGEPROTEC, \\ Universidade de Caxias do Sul - UCS, Rua Francisco Getúlio Vargas, 1130, \\ CEP 95070-560, Caxias do Sul, RS, Brazil \\ ${ }^{b}$ Postgraduate Program in Mining, Metals and Materials Engineering - PPGE3M, \\ Universidade Federal do Rio Grande do Sul - UFRGS, Av. Bento Gonçalves, 9500, \\ CEP 91501-970, Porto Alegre, RS, Brazil
}

Received: February 5, 2014; Revised: November 12, 2014

The objective of this study is to develop expanded composites of poly(ethylene-co-vinyl acetate) (EVA) filled with two vegetable reinforcements (banana fiber or wood flour) as well as to evaluate the influence of the type, size and concentration of these reinforcements on the cell growth and their morphological, mechanical, thermal and physical properties. The results indicated that the natural fibers act as nucleating agents and affect the cells stability during the formation of the cellular structure in the expanded composites. The mechanical properties of the expanded composites are directly related to the composite expansion degree. Comparative results of the use of vegetable residues indicate that wood flour reinforcement provides more homogeneous cells, while banana fibers restrict the expandability of the composite and its density.

Keywords: expanded composite, wood flour, banana fiber, EVA, blowing agent

\section{Introduction}

The interest in the use of vegetable fibers has grown significantly in recent years due to their potential applications as reinforcing agents in polymer composites and the huge potential for replacing inorganic fibers (e.g., glass fiber) and fillers (e.g., calcium carbonate). The use of vegetable fibers is beneficial to the environment due to their renewability and biodegradability properties, and in addition, vegetable fibers are endowed with highly desirable properties, such as, non-toxicity and lower density and abrasiveness compared to inorganic fibers ${ }^{1}$.

Several natural fibers have been used as reinforcement agents in polymeric composites with natural fibers. Among these fibers, wood flour (WF) is the most widely used in thermoplastic composites, and it is gaining increasing acceptance because of its good mechanical properties, low cost and easy processing ${ }^{2}$. Banana fibers (BF) are abundant in tropical countries, being extracted from the pseudostem of the banana plant, which is usually cut and discarded after the fruit is harvested. BF originates from the residue of the cultivation of bananas, and if not properly treated, this banana plantation waste may enable the proliferation of fungi due to its high moisture content and the considerable time required for its degradation ${ }^{3,4}$.

Polymeric composites are materials consisting of two or more phases; usually, the polymer is the continuous phase (matrix) and the fiber is the reinforcing one $e^{5}$. But, generally,

*e-mail: matheus.vgz@gmail.com these composites exhibit much higher density than do those of raw wood; thus, several alternative processes have been proposed to reduce the density of polymeric composites with natural fibers, such as the use of expanding blowing agents. In expanded polymer composites or cellular polymeric composites, there is a third phase that is characterized by voids (cellular structure) formed by the action of a blowing agent on the polymer matrix ${ }^{6}$.

The expanded composite production process is usually associated with the incorporation of a blowing agent during the composite processing. Blowing agents that enable the formation of a cellular structure in the polymer matrix may be physical, such as low boiling point liquids, or solid chemical compounds that decompose under heat with the release of gases such as nitrogen and carbon dioxide ${ }^{7,8}$

The formation of cells in the expanded composites is also influenced by the characteristics of the vegetable fiber, as well as the existence of micropores or voids in the polymer-fiber interface that enable the migration of the gas generated by the blowing agent to these regions and thereby promote cell initiation and propagation from the micropores. Rizvi et al. ${ }^{9}$ observed that the presence of moisture and extractives in wood particles contribute to the initiation of cell nucleation. The volatilization of moisture and extractives from vegetable fibers occuring below $175^{\circ} \mathrm{C}$ (which is the customary processing temperature) generates a small amount of gas, which generally migrates to the polymer-fiber interfacial region and thereby initiates the 
formation of a small void space. The gas from the blowing agent migrates to the void initiation region in the polymerfiber interface and propagates the cell growth from this region. Thus, a larger amount of WF particles provides increased nucleation sites for new cell formation during the foaming of the composite.

Doroudiani and Kortschot ${ }^{10}$ reported that different cellular morphologies can be obtained depending on the type, size and concentration of the vegetable fiber used in the cellular composite. Expanded composites can undergo large compressive deformations and thus absorb considerable amounts of specific energy. Energy dissipation (mechanical and/or thermal) is directly influenced by the cell size to fiber size ratio in the expanded composite. When the expanded composite is exposed to mechanical deformation, energy can be absorbed and dissipated by the cellular structure, fiber pull-out, matrix fracture or dislocation of the fiber in the matrix at the polymer-fiber interfacial region. For example, in compression strength testing, as shown in Figure 1, energy can be dissipated through cell bending or buckling or through matrix fracture.

The compression strength curve of a semi-rigid cellular system exhibits three well-defined regions: (I) a linear elasticity region, (II) a plateau and (III) a densification region. The elastic deformation region is controlled by cell wall bending and buckling, which fully recover upon removal of the load and does not cause the breaking of the material. With increasing compressive load, the cells begin to collapse and disappear, and the foam quickly becomes denser; this phase is characterized by a long plateau in the stress-strain curve, in which the foam deforms with virtually no density increase. In the third stage, commonly referred to as the densification region, tension increases rapidly without any significant increment in deformation because most of the cells are collapsed; as a result, the composite matrix begins to be compressed, which causes the rapid increase of the resistance of the sample ${ }^{11}$.

The most commonly used polymer matrices in the production of expanded composites with vegetable fibers are polyethylene (PE), polypropylene (PP) and poly(vinyl chloride) (PVC). However, few studies have reported the use

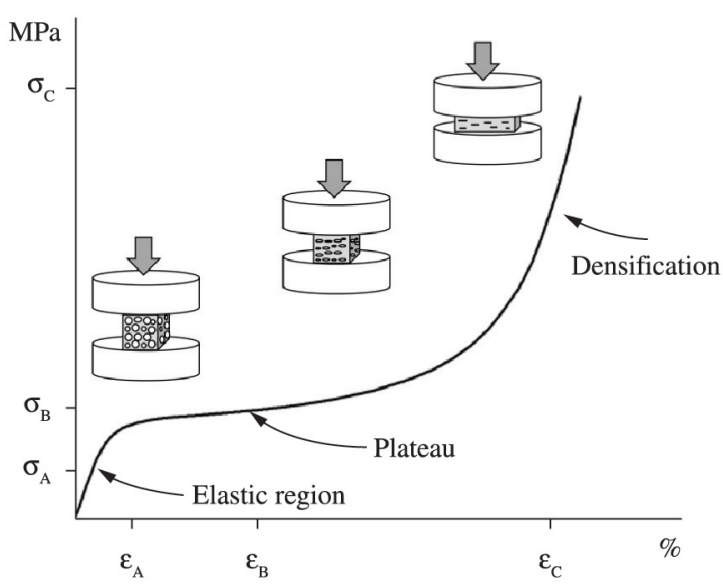

Figure 1. Schematic compression-stress-strain curve for a polymer expanded composite. of poly(ethylene-co-vinyl acetate) (EVA) as a matrix in the development of expanded composites with vegetable fibers. Properties of the EVA copolymer are intermediate to those of its two constituent homopolymers, that is, polyethylene and poly(vinyl acetate), it being one of the most widely used thermoplastic matrices for foamed plastics. Thus, the objectives of this study are to develop a semi-rigid expanded composite of EVA filled with two different types of vegetable fibers - BF and WF - and to evaluate the influence of these fibers on the properties of the resulting expanded composites.

\section{Material and Methods}

\subsection{Materials}

Poly(ethylene-co-vinyl acetate) (EVA), grade 1825 with $18.8 \%$ vinyl acetate (VA), was supplied by Quattor S.A. (Braskem, S.A.). The coupling agent PEgMA, grade Polybond 3029, was supplied by Chemtura. The chemical blowing agent azodicarbonamide (ACA) activated with zinc oxide $(\mathrm{ZnO})$ was supplied by Inbra Industria Química Ltda (decomposition temperature of between 160 and $180^{\circ} \mathrm{C}$ ). The crosslinking agent (dicumyl peroxide), grade DCP $40 \mathrm{SAP}$ (processing temperature $-180^{\circ} \mathrm{C}$ ), and the lubricant (Lub), grade Retiflux, were supplied by Retilox Química especial Ltda. The banana fibers (BF) were obtained by the extraction of the pseudostem of the banana tree, type prata, collected in southern Brazil/RS. The fibers were washed with an alkaline solution of $1 \%(\mathrm{w} / \mathrm{v}) \mathrm{NaOH}$ for $1 \mathrm{~h}$ at room temperature, and thereafter the fibers were rinsed with distilled water, dried in an oven at $70^{\circ} \mathrm{C}$ for $24 \mathrm{~h}$ and cut into 2-cm-length pieces. The wood flour (WF) was collected from the stem of a Eucalyptus dunnis tree. The wood was previously dried in an oven at $70^{\circ} \mathrm{C}$ for $5 \mathrm{~h}$ and milled in a MARCONI model MA 580 knife mill. The wood samples were separated in a particle size classifier to particle sizes of $80-150$ mesh ( 0.177 to $0.099 \mathrm{~mm})$ and dried in an oven at $70^{\circ} \mathrm{C}$ for $24 \mathrm{~h}$.

\subsection{Sample preparation}

The sample composition is described in Table 1. By weight, 2\% of PEgMA as a compatibilizing agent was added to EVA using a single screw extruder (SEIBT model ES35, L/D 20) with a temperature profile of 90, 120 and $140^{\circ} \mathrm{C}$ and a screw speed of $60 \mathrm{rpm}$. The beneficial use of compatibilizing agents, such as maleic anhydride, grafted on a polymer matrix has been widely discussed in the literature ${ }^{12-14}$, and as such it is not the focus of this study and will not be further elaborated below.

Additives and fillers were incorporated into EVA / PEgMA using an open two-roll-mill (COPE, model Lab Mill), pre heated at $85^{\circ} \mathrm{C}$ in the front cylinder and at $65^{\circ} \mathrm{C}$ in the back cylinder to prevent the accession of the band to the back roller. The mixing process entailed sequentially adding each formulation component in the following order: EVA, fillers (BF or WF), lubricant, activator $(\mathrm{ZnO})$, blowing agent azodicarbonamide (ACA) and crosslinking agent (DCP). The duration of the mixing ranged from 10 to $12 \mathrm{~min}$.

After mixing, the composites were formed into preforms using a thermal press (SCHULZ) at $115^{\circ} \mathrm{C}$, at 
Table 1. Compositions of the samples with and without reinforcement agents, in parts per hundred parts of resin (phr).

\begin{tabular}{lcccccc}
\hline \multicolumn{1}{c}{ Sample } & EVA + PEgMA & BF & WF & ACA / ZnO & DCP & Lub \\
\hline e-EVA & $98 / 2$ & - & - & $2 / 1$ & $2 / 1$ & 2 \\
e-EVA/BF 10 & $98 / 2$ & 10 & - & $2 / 1$ & 2 & 1 \\
e-EVA/BF 20 & $98 / 2$ & 20 & - & $2 / 1$ & 2 & 1 \\
e-EVA/BF 30 & $98 / 2$ & 30 & 10 & $2 / 1$ & 2 & 1 \\
e-EVA/WF 10 & $98 / 2$ & - & 20 & $2 / 1$ & 2 & 1 \\
e-EVA/WF 20 & $98 / 2$ & - & 30 & 2 & 1 \\
e-EVA/WF 30 & $98 / 2$ & - & & & & 1 \\
\hline
\end{tabular}

$\mathrm{WF}=$ Wood flour, $\mathrm{BF}=$ Banana Fiber, $\mathrm{e}=$ expanded.

5 tons of pressure for $5 \mathrm{~min}$ using a $140 \times 160 \times 3 \mathrm{~mm}$ mold. The average mass of the preform used was $80 \pm 2 \mathrm{~g}$. The preform was then placed in a $150 \times 170 \times 12 \mathrm{~mm}$ mold for free expansion in the absence of an applied pressure at $175^{\circ} \mathrm{C}$. The residence time of the samples in the heat press was $40 \mathrm{~min}$.

\subsection{Sample characterization}

The samples were characterized using physical, mechanical and thermal testing. The physical tests included the measurement of the apparent density of the foams in accordance with the ASTM Method D1622-14 ${ }^{15}$. The measurements were performed at seven different regions of the expanded plate at $21^{\circ} \mathrm{C}$. To monitor the absorption of water of the expanded composites, cubic shaped $(10 \times 10 \times 10 \mathrm{~mm})$ test specimens were dried overnight at $60^{\circ} \mathrm{C}$ up to constant weight. Next, they were immersed in static distilled water at $21^{\circ} \mathrm{C}$. The absorption of water by the sample at time $t$ was calculated using Equation $1^{16,17}$, after $2,5,24,48$ and $72 \mathrm{~h}$ of water immersion.

$\%$ water absorption $=\left(M_{T}-M_{0}\right) / M_{0} \times 100$

Where $M_{T}$ is the mass of the samples at time $t$, and $M_{0}$ is the mass of the samples before water immersion. The water absorption was plotted as a function of time.

The surface morphology of the expanded composites was characterized by scanning electron microscopy (SEM -Shimadzu SuperScan SS-550). The samples were coated with $\mathrm{Au}$, and the software used to measure the cell size was Image Tools for Windows, version 3.00. The cell population density per unit volume of the foamed composites $(N f)$ was determined with the aid of the parameters extracted from the SEM micrographs using Equations 2 and $3^{11}$.

$V f=\left(1-\left(\frac{\rho f}{\rho p}\right)\right)$

$N f=\left(\frac{n M^{2}}{A}\right)^{3 / 2} \cdot\left(\frac{1}{1-V f}\right)$

Where $V f$ is the void fraction (\%), $\rho p$ is the density of the rigid (unfoamed) composite $\left(\mathrm{g} \cdot \mathrm{cm}^{-3}\right), \rho f$ is the foam density $\left(\mathrm{g} \cdot \mathrm{cm}^{-3}\right), N f$ is the cell density $\left(\right.$ cells $\left.\cdot \mathrm{cm}^{-3}\right), M$ is the magnification factor of the micrograph, $n$ is the number of bubbles (cells) in the SEM micrograph and $A$ is the area of the micrograph $\left(\mathrm{cm}^{2}\right)$.
Mechanical tests included tear strength assessment performed on the expanded composites with a EMIC DL2000 universal testing machine in accordance with the ASTM D624-00(2012) standard ${ }^{18}$. The test speed was $500 \mathrm{~mm} \cdot \mathrm{min}^{-1}$ with a load cell of $20 \mathrm{kN}$. Type $\mathrm{C}$ of the tear strength model was used, and the test was performed on five specimens for each sample. Hardness was measured on the sample surface (skin) using Shore A scale and on the core using Shore O scale. The hardness test was conducted using a TECLOCH tester, Model GS 702, Type A and Type O, according to the ASTM D2240-05(2010) standard ${ }^{19}$. The test was performed on 10 different locations outside and inside the expanded plate. The compressive strength test was applied by adapting the ASTM D1621-10 standard $^{20}$; it was used to test specimens of $50 \times 50 \times 10 \mathrm{~mm}$ size, and the test speed was $1.3 \mathrm{~mm} . \mathrm{min}^{-1}$. The compressive strength was evaluated under tension at 10,30 and $75 \%$ deformation.

The melt flow index (MFI) of the unfoamed composites was measured without the addition of either a blowing agent or a dicumyl peroxide crosslinking agent. The experiment was conducted using a DYNISCO Kayeness Test Systems instrument model D4001 $\mathrm{Hv}$ at a temperature of $190^{\circ} \mathrm{C}$ and $2.16 \mathrm{kgf}$ according to the ASTM D1238-13 standard $^{21}$.

Thermogravimetric analysis of the samples was performed using a SHIMADZU Model 50-TGA instrument at a heating rate of $10^{\circ} \mathrm{C} \cdot \mathrm{min}^{-1}$ and heating ramp from 0 to $600^{\circ} \mathrm{C}$ under a $\mathrm{N}_{2}$ atmosphere $\left(50 \mathrm{~mL} \cdot \mathrm{min}^{-1}\right)$. The moisture and extractives content were determined by the average value of three thermograms for each sample tested.

\section{Results and Discussion}

\subsection{Morphology of the cellular composites}

Figure 2 shows the SEM micrographs of the expanded composites of EVA with BF and WF, and Table 2 presents the mean values of the cell parameters.

From the SEM micrographs of the cut surface of the expanded composites, the heterogeneous morphology of the cells was observed, which consists of open and closed cells of different shapes and sizes. The formation of such irregular, heterogeneous cells in the expanded composites is influenced by the type of chemical blowing agent, the presence of vegetable fillers (WF and BF) of irregular particle shapes as well as moisture and extractives volatilization (from either of the vegetable fillers used) during the heating ${ }^{8,17}$. The extractives present in the vegetable fibers are composed of different materials, including resins, waxes and tannins. Moisture and extractives are volatilized and 


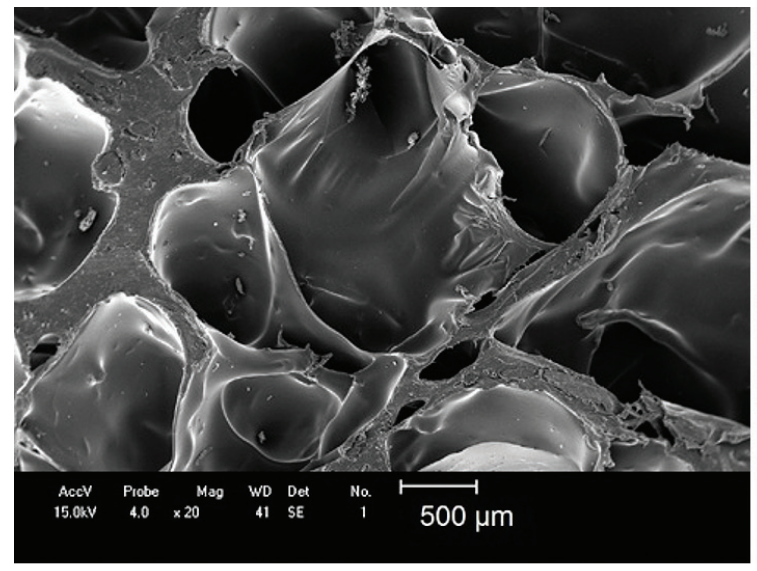

(a)

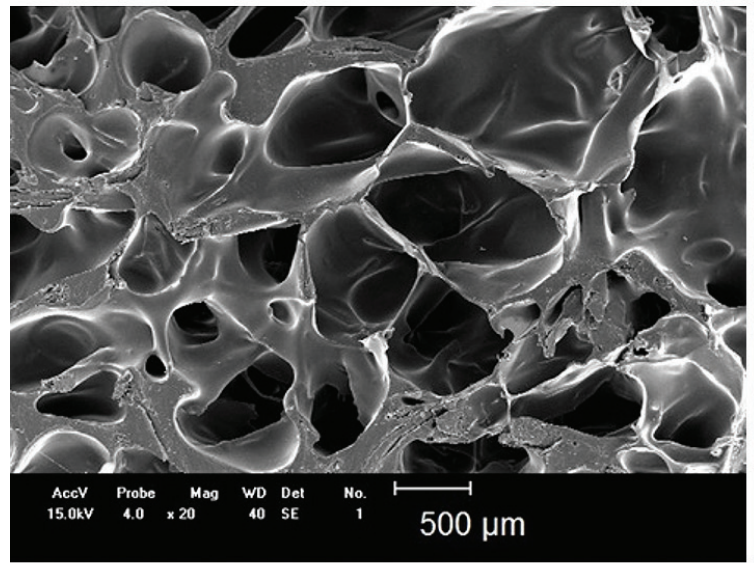

(b)

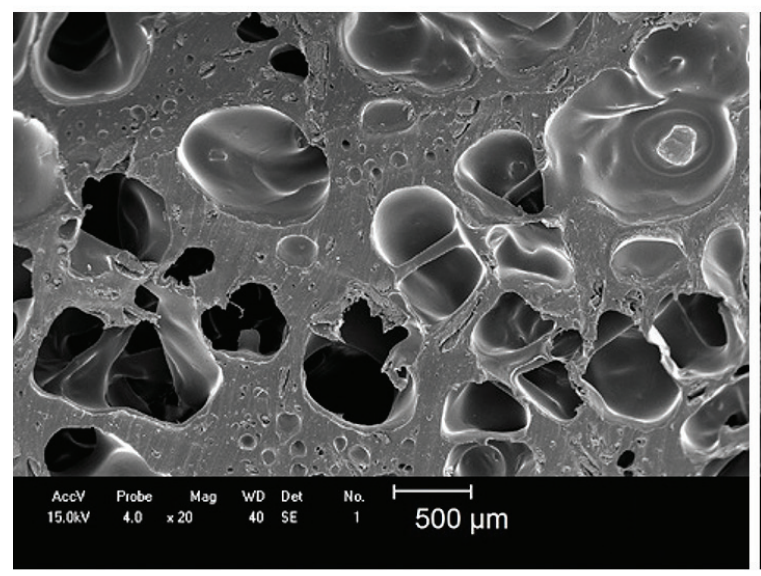

(c)

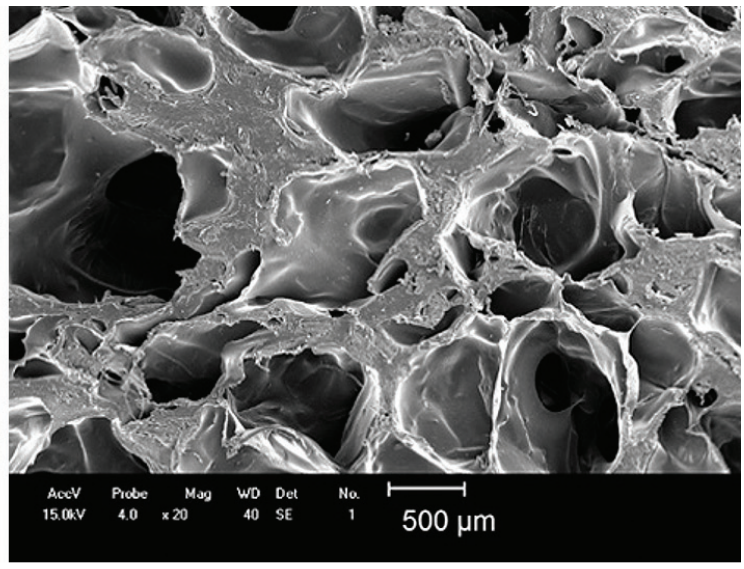

(d)

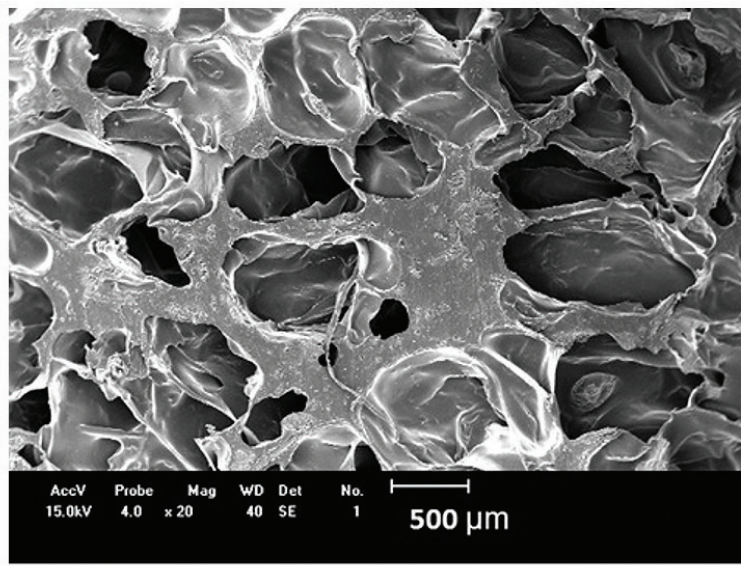

(e)

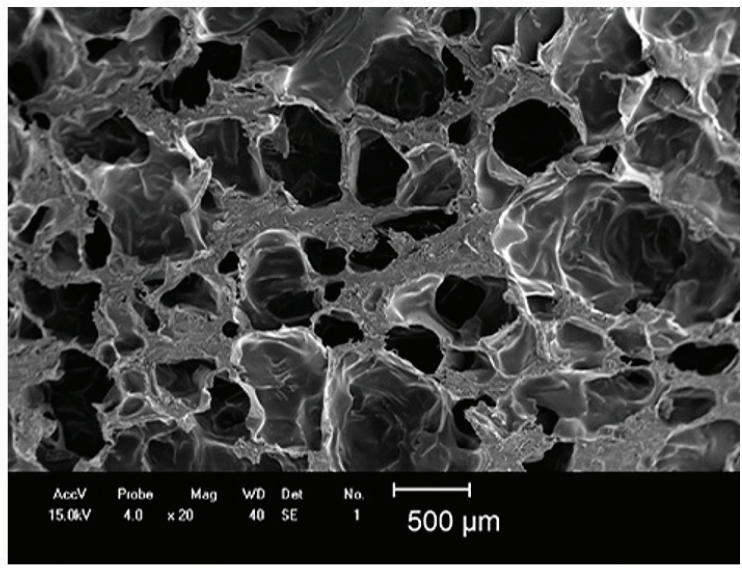

(f)

Figure 2. SEM micrographs at $20 \times$ magnification of (a) e-EVA/BF 10, (b) e-EVA/BF 20 and (c) e-EVA/BF 30, (d) e-EVA/WF 10, (e) e-EVA/WF 20 and (f) e-EVA/WF 30.

condensed at different temperatures and times from those of the blowing agent; thus, when moisture and extractives condense, vacuum can form inside the cells as they cool, thereby damaging the structure of the cell composite. Another factor that can lead to the formation of irregular cells is the free-expansion pressure process used to expand the composites, which favors the formation of vertically oriented oval cells. Further, poor dispersion of the fillers in the matrix can also boost the formation of irregular cells.

For WF- filled composites, cell size decreases and $\mathrm{Nf}$ increases with increasing fiber content because the fiber acts as a nucleating agent during expansion, as also observed by 
Table 2. Cell size frequency distribution in the cellular composites.

\begin{tabular}{ccccc}
\hline Sample & Cell size variation $(\boldsymbol{\mu m})$ & $\begin{array}{c}\text { Average cell } \\
\text { diameter }(\boldsymbol{\mu m})\end{array}$ & $\begin{array}{c}\text { Number of cells per } \\
\text { micrograph } \\
\left(\mathbf{a r e a ~ - ~ 2 2 . 7} \mathbf{~ m m} \mathbf{m}^{2}\right)\end{array}$ & $\begin{array}{c}\text { Cell density } \boldsymbol{N f} \\
\left(\mathbf{c e l l} \cdot \mathbf{c m}^{-3}\right)\end{array}$ \\
\hline e-EVA/WF 10 & $538-1385$ & $848 \pm 244$ & $10 \pm 2$ & $5.5 \times 10^{6}$ \\
e-EVA/WF 20 & $269-1346$ & $671 \pm 238$ & $23 \pm 7$ & $19.6 \times 10^{6}$ \\
e-EVA/WF 30 & $115-1192$ & $454 \pm 232.8$ & $30 \pm 5$ & $35.0 \times 10^{6}$ \\
e-EVA/BF 10 & $576-2307$ & $1179 \pm 441$ & $11 \pm 3$ & $8.6 \times 10^{6}$ \\
e-EVA/BF 20 & $269-1576$ & $770 \pm 296$ & $18 \pm 5$ & $10.2 \times 10^{6}$ \\
e-EVA/BF 30 & $230-1192$ & $639 \pm 259$ & $15 \pm 3$ & $7.7 \times 10^{6}$ \\
\hline
\end{tabular}

Rodrigue et al. $^{6}$ in the study of the effect of the presence of wood flour on the nucleation of polymer foams. Thus, increasing WF content creates cells that are both more numerous and of smaller size. On the other hand, for expanded composites produced with $\mathrm{BF}$, a steep increase in $N f$ with 20 and $30 \mathrm{phr}$ of BF was not observed due to the low expansion capacity of these composites. The low expansion capacity can result from the presence of larger number of polymer moieties and fewer cells in the expanded composite as shown in the micrographs of Figure $2 \mathrm{c}$. The presence of $\mathrm{BF}$ may have restricted the mobility of the composite matrix during expansion, thereby inhibiting expansion of the cells. Since BF are longer than those of WF, the actual surface area is much smaller, and consequently, BF has less regions which favor cell initiation.

The increase in the amount of fibers and filler also influences the viscosity of the expanded composites, being directly related to the expansion process and the mechanical properties of the expanded composite ${ }^{3,6}$, as will be shown later in the Melt Flow Index topic.

Figure 3 shows the cell size frequency distribution according to the fiber content in the expanded composites, which reveals the tendency of the formation of smaller cells with increasing WF content in the expanded composite. Comparing the two expanded composites, taking into consideration the different contents of $\mathrm{BF}$ and $\mathrm{WF}$, those produced with BF generally had larger cell diameters compared to those made with WF, and the expanded composites produced with WF have higher concentration of cells per unit area than those produced with BF.

Figure 4 shows the dispersion of BF and WF in the expanded composite. Figure $4 \mathrm{a}$ and $4 \mathrm{~b}$ show that BFs are dispersed either on the cell walls or in the middle of the cell, thereby perforating the cell. This distribution also affects the expansion capacity of the expanded composites. The BFpolymer interfaces exhibit moderate adhesion; voids can still be observed in the region of the fiber-polymer interface, even after the addition of a compatibilizing agent and alkaline treatment of the BFs. Arrows indicate the position of the $\mathrm{BF}$ in the expanded composite, which may be arranged in the contour of the cells (Figure $4 \mathrm{a}$ ) or punching them (Figure 4b). WF is preferentially deposited on the cell wall, and in contrast to BF, no voids were observed between the polymer and the fiber in the micrographs of these samples.

Figure $4 d$ shows the presence of skin on the surface of the expanded composite (in this case, e-EVA/WF-20). A thicker region relative to the upper end of the sample is clearly present. This region exhibits a higher polymeric mass concentration and sparsely packed cells. The formation of this region is attributed to the restriction of the mold to the growth of the expanded composite, thereby encouraging condensation of the polymer regions as a result of the gas pressure of the blowing agent.

\subsection{Physical and mechanical properties}

The densities and mechanical properties of the expanded composites are listed in Table 3.

The apparent density of the foam characterizes the ratio between the solid and gas contents of the foam and directly affects its physical, mechanical, thermal, acoustic and electrical properties. The density of e-EVA free of fillers is $0.34 \pm 0.03 \mathrm{~g} \cdot \mathrm{cm}^{-3}$. The expanded composite produced with BF had higher density with increased fiber content, which is most likely caused by the increase in the viscosity of the polymer mass, due to the presence of BF that restricts its expansion, as observed in the previous micrographs. The density of the expanded composites produced with WF was similar, even with a variation of the WF content, most likely because the viscosity was sufficient for the expansion to occur and fill the mold in all the samples. However, this apparent density is merely an average of the physical properties of the expanded composite, as the density of the surface and that of the core of the expanded composites can be different ${ }^{22}$.

The mechanical properties of tear strength of the expanded composites filled with BF were slightly improved when compared to e-EVA and were lower for the WF-filled composites relative to the properties of e-EVA. The increase in tear strength of the expanded composites filled with BF is related to their low expansion capacity, higher density, poor cell population and the BF influence.

The compressive strength of the expanded composites exhibited a gradual increase with increasing content of either of the vegetable reinforcements studied. Based on the behavior of the stress-strain curve shown in Figure 1, the stress at $10 \%$ deformation, related to the reversible deformation of the expanded composites, did not change significantly with increasing WF content; in contrast, more pronounced increase in stress was observed in the e-EVA/ BF samples filled with 20 and 30 phr of BF. Compressive tension at $30 \%$ of deformation, which is related to the influence of the cellular structure, exhibited superior results in the e-EVA/WF composites when compared to the e-EVA/ $\mathrm{BF}$ composites. This result can be related to the presence of 


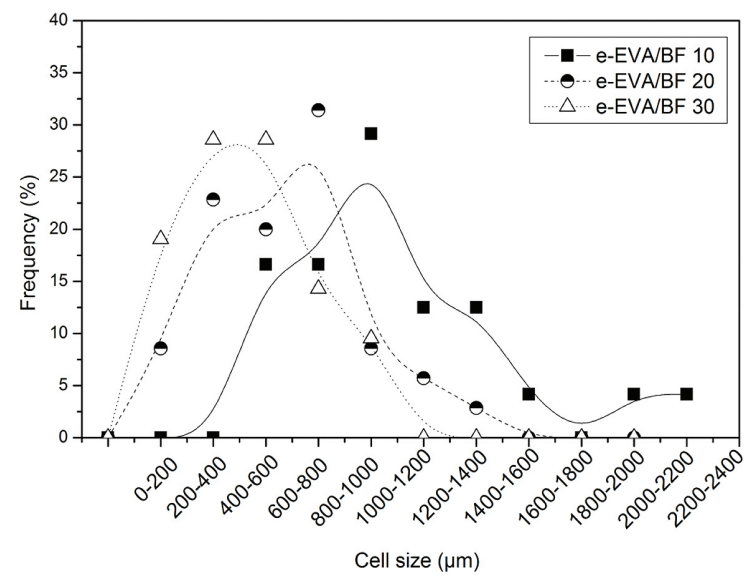

(a)

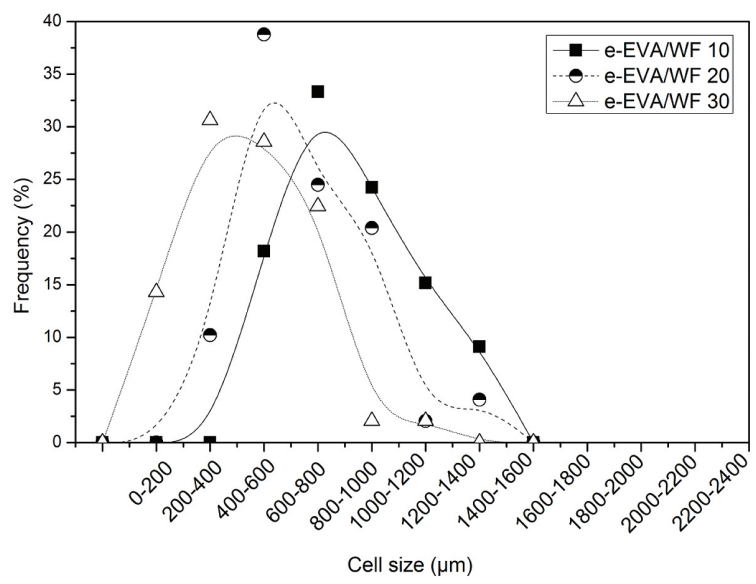

(b)

Figure 3. Cell size frequency distribution in cellular composites produced with (a) BF and (b) WF.

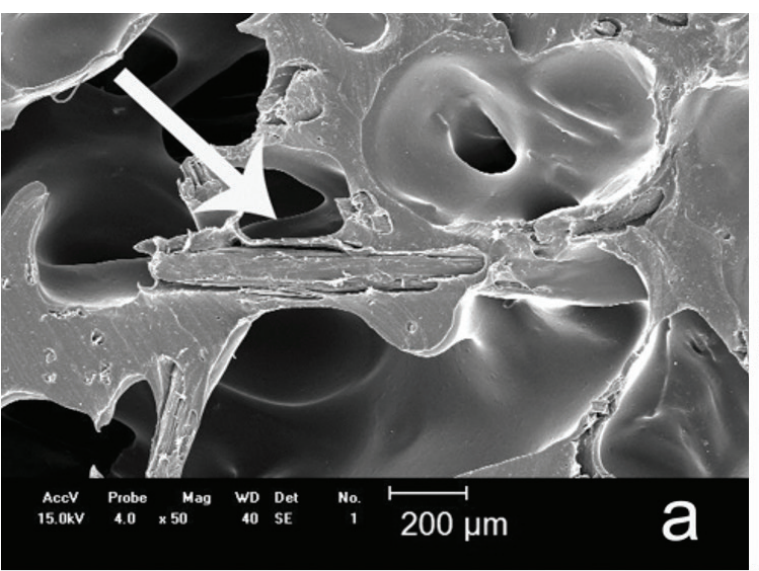

(a)

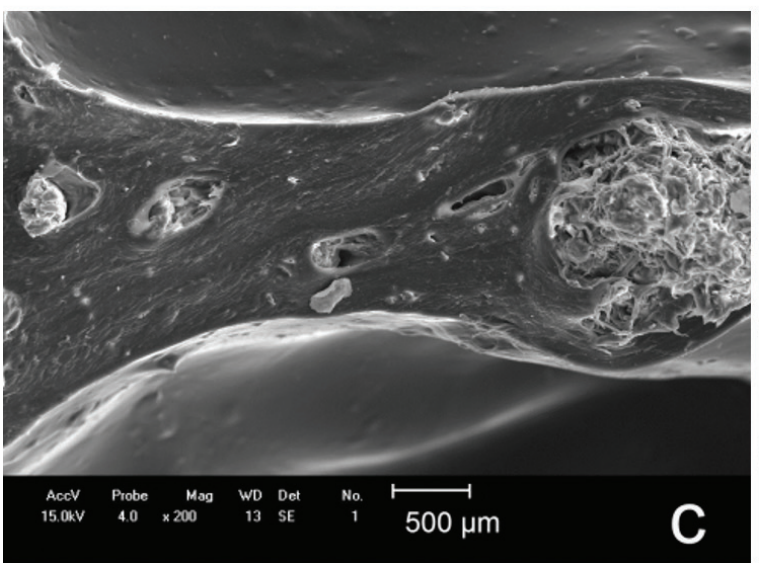

(c)

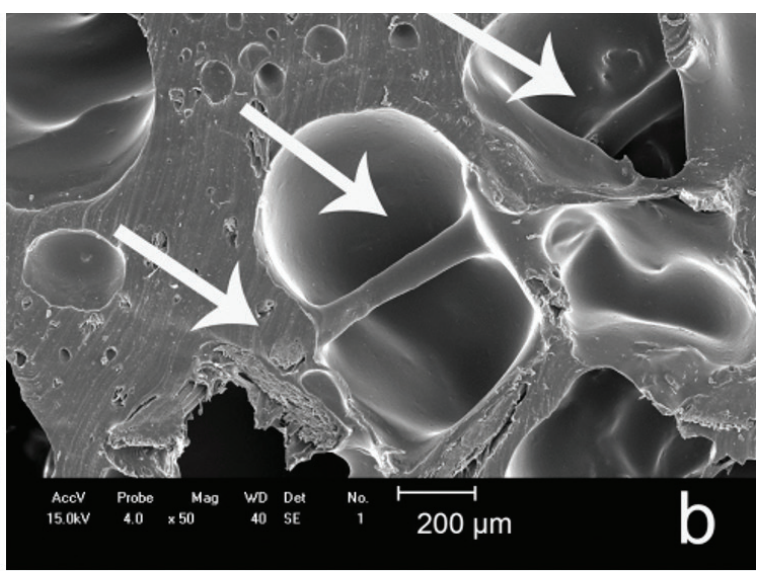

(b)

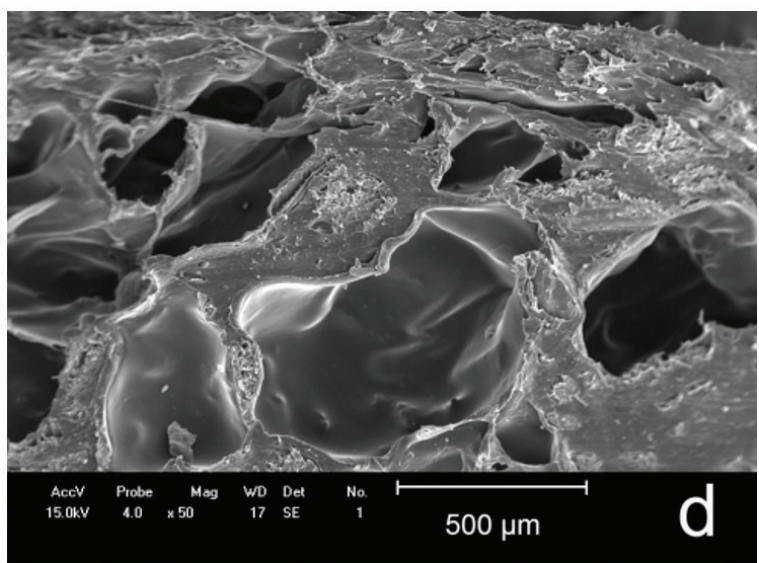

(d)

Figure 4. SEM images: (a) and (b) two locations of e-EVA/BF-20 at $50 \times$ magnification; (c) e-EVA/WF-20 at $200 \times$ magnification; (d) surface (skin) of e-EVA/WF-20 at $50 \times$ magnification. 
Table 3. Physical and Mechanical properties of the expanded samples.

\begin{tabular}{|c|c|c|c|c|c|c|c|}
\hline Sample & $\begin{array}{l}\text { Density } \\
\left(\mathrm{g} / \mathrm{cm}^{3}\right)\end{array}$ & $\begin{array}{c}\text { Tear Strength } \\
(\mathrm{N} / \mathrm{mm})\end{array}$ & $\begin{array}{c}\text { Compression } \\
\text { Set } 10 \% \\
(\mathrm{MPa})\end{array}$ & $\begin{array}{c}\text { Compression } \\
\text { Set } 30 \% \\
\text { (MPa) }\end{array}$ & $\begin{array}{c}\text { Compression } \\
\text { Set } 75 \% \\
(\mathrm{MPa})\end{array}$ & $\begin{array}{l}\text { Hardness } \\
\text { in Nucleus } \\
\text { (Shore O) }\end{array}$ & $\begin{array}{c}\text { Hardness in } \\
\text { Skin } \\
\text { (Shore A) }\end{array}$ \\
\hline e-EVA & $0.34 \pm 0.03$ & $21.7 \pm 1.6$ & $0.05 \pm 0.01$ & $0.10 \pm 0.01$ & $0.41 \pm 0.01$ & $39.4 \pm 5.4$ & $25.3 \pm 5.3$ \\
\hline e-EVA/WF 10 & $0.35 \pm 0.02$ & $15.8 \pm 3.5$ & $0.15 \pm 0.01$ & $0.38 \pm 0.06$ & $2.87 \pm 0.35$ & $68.5 \pm 6.5$ & $53.8 \pm 4.0$ \\
\hline e-EVA/WF 20 & $0.37 \pm 0.02$ & $16.3 \pm 2.3$ & $0.19 \pm 0.02$ & $0.50 \pm 0.08$ & $3.58 \pm 0.51$ & $76.5 \pm 2.8$ & $55.9 \pm 7.4$ \\
\hline e-EVA/WF 30 & $0.33 \pm 0.04$ & $13.4 \pm 1.4$ & $0.18 \pm 0.01$ & $0.65 \pm 0.05$ & $3.99 \pm 0.44$ & $79.8 \pm 4.1$ & $59.0 \pm 6.3$ \\
\hline e-EVA/BF 10 & $0.38 \pm 0.02$ & $23.3 \pm 1.9$ & $0.09 \pm 0.01$ & $0.34 \pm 0.02$ & $2.97 \pm 0.63$ & $53.4 \pm 6.2$ & $39.5 \pm 9.1$ \\
\hline e-EVA/BF 20 & $0.50 \pm 0.02$ & $21.1 \pm 3.1$ & $0.23 \pm 0.08$ & $0.46 \pm 0.05$ & $3.69 \pm 0.41$ & $76.4 \pm 4.3$ & $65.5 \pm 3.4$ \\
\hline e-EVA/BF 30 & $0.74 \pm 0.08$ & $30.1 \pm 2.5$ & $0.31 \pm 0.04$ & $0.59 \pm 0.03$ & $4.46 \pm 0.39$ & $87.0 \pm 2.6$ & $69.7 \pm 2.6$ \\
\hline
\end{tabular}

a larger number of cells in the WF composites, which was observed in the morphological assays via SEM images. The compressive tension at $75 \%$ deformation, which is related to the influence of the matrix and both reinforcement agents, did not change significantly between the e-EVA/BF and e-EVA/WF composites, except in the case of the e-EVA/ $\mathrm{BF} 30$ sample that exhibited higher results compared to the other samples.

In general, hardness of the expanded polymer composites depends on the polymer matrix and its cell structure ${ }^{23}$. Surface (skin) hardness of the expanded composite is higher than that of its interior because it has a more condensed polymer mass and fewer cells. Measuring hardness on the skin and in the core required the use of a durometer having Shore A and Shore O scales, respectively. Expanded composites produced with BF tend to have higher hardness both on the surface (skin) and inside (core) because of the lower expansion capacity for the composites of higher fiber contents. Thus, more physical regions (polymer and fiber) and fewer gaseous regions (cells) are formed, which increases hardness. Hardness in the core of the expanded composites produced with WF exhibit proximity and stability because their cellular morphology and density are more similar than those of the composites produced with BF. The e-EVA/WF composite also tends to have a harder surface with increasing WF content. The expanded composites produced with BF and WF both had higher hardness values compared to e-EVA due to the ability of both fillers to act as reinforcing agents, thus providing improved hardness to the expanded composites ${ }^{23}$.

\subsection{Melt Flow Index - MFI}

The melt flow index is inversely proportional to the viscosity of the composite and its flowability under the action of temperature and pressure ${ }^{24,25}$. MFI values for EVA and each of the composites with a vegetable reinforcement agent are shown in Figure 5.

When increasing the filler content in the composites, MFI decreases due to the presence of load limits to the molecular chains mobility of the polymer composite, thus causing an increase in the composite viscosity. Among the $\mathrm{BF}$ and WF-filled composites the addition of BF, due to the larger fiber size, was observed to further limit the mobility of the polymer chains in the molten state when compared to WF, which ultimately causes an increase in the viscosity and a decrease in their MFI properties.

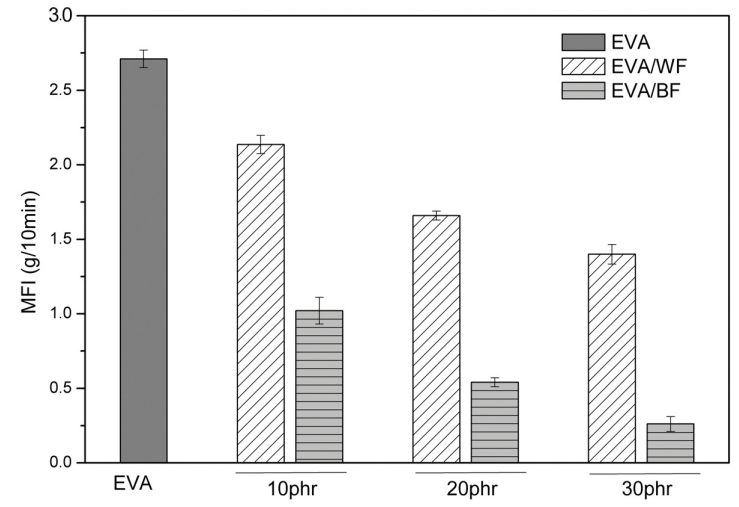

Figure 5. MFI for EVA, EVA/WF and EVA/BF composites.

\subsection{Thermogravimetry - TGA}

Figure 6 shows the thermal properties of EVA, BF, WF and their respective expanded composites. e-EVA has two mass loss events due to its two distinct monomers. The first weight loss, which is observed between 348 and $391{ }^{\circ} \mathrm{C}$, is related to the decomposition of vinyl acetate, and the second weight loss that occurs between 465 and $495^{\circ} \mathrm{C}$ corresponds to the thermal degradation of the polyethylene fraction in the copolymer.

Both vegetable fibers ( $\mathrm{BF}$ and $\mathrm{WF}$ ) exhibited three mass loss stages. The first stage, which occurs below $100^{\circ} \mathrm{C}$, is related either to the evaporation of water and/or the volatilization of the extracts present in the natural fibers. The second stage is the degradation of polysaccharides and hemicellulose, the breakage of the glycolic connections of the cellulose and the beginning of lignin degradation. The third stage involves the complete degradation of lignin and cellulose $\mathrm{e}^{26,27}$

As described above, the presence of moisture and the volatilization of extractives contribute to irregular cell formation and nucleation of the cells during the preparation of the composites ${ }^{8,23}$. The weight loss up to $175^{\circ} \mathrm{C}$ (i.e., the temperature used in the expansion process) was $7.8 \pm 0.7 \%$ for WF and $4.6 \pm 0.5 \%$ for BF. The BF composite exhibited lower mass loss in this region than did the WF composite, most likely because the alkaline treatment extracted most of the extractives volatile in this temperature range, as both fibers were dried under the same conditions before testing. 
Guo et al. ${ }^{24}$ reported that it is very difficult to remove all of the volatiles without causing degradation of a vegetable fiber. Wood and vegetable fibers contain three different categories of water. The first is the absorbed water contained in the cell lumens, such as the liquid water contained in a recipient. The second category is the adsorbed water (or bound water) that is present in the cell walls and is held in place by the molecular attractive forces. The third category is the water of constitution that exists as part of the molecular structure of the wood, in the form of hydrogen and hydroxyl groups, which is split off and forms water under prolonged heating ${ }^{8,24}$.

With respect to the thermal properties of the cellular composites, both composites produced with BF and WF exhibit thermal stabilities with characteristics intermediate to the polymer and the constituent fibers. Increasing the fiber content corresponds to reduction in the thermal stability of both types of cellular composites. These intermediate properties may indicate that the cellular composites are highly homogeneous in terms of the constituent materials ${ }^{23}$.

\subsection{Water absorption}

Water absorption as a function of time for e-EVA and the expanded composites is presented in Figure 7. In general, e-EVA exhibits constant water absorption over the study period, whereas the samples with vegetable fibers tend to exhibit increased water absorption for both increased fiber content and water exposure time.

The mixed open and closed cell morphology enables water infiltration into the interior of the composite cell. However, even with fewer cells, the e-EVA/BF samples exhibited higher tendency to absorb water than the sample with wood flour, probably due to the higher hydrophilicity of BF compared to that of WF. The alkaline treatment promoted the extraction of less stable components of BF, such as a portion of hemicellulose, lignin, wax and oils, thus leading to the formation of a more porous structure in the BF composites compared to the WF composites. The formation of higher concentration of $\mathrm{OH}$ groups from the remaining cellulose provides increased capacity to absorb water on the surface of the BF composites compared to that of the WF composites ${ }^{28,29}$.

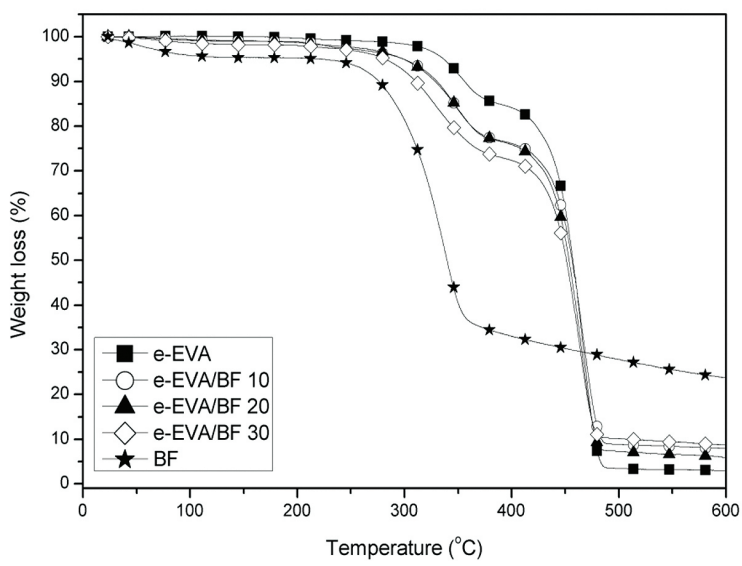

(a)

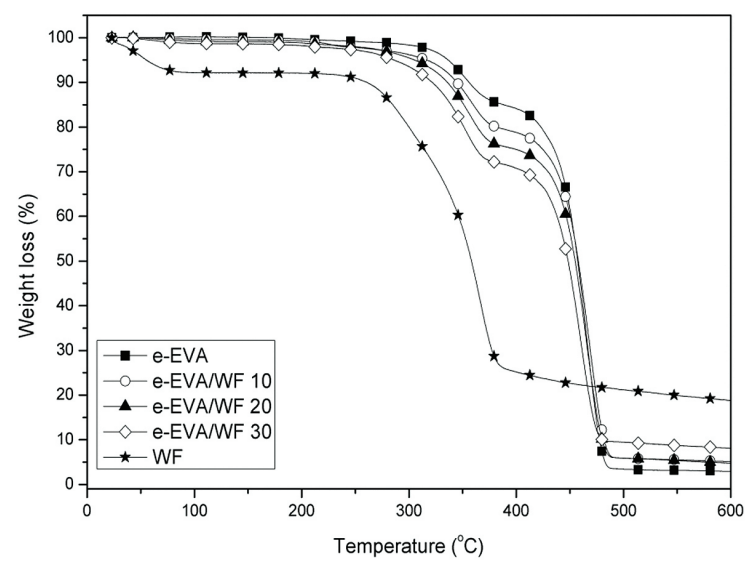

(b)

Figure 6. TGA and DTG of e-EVA compared to (a) e-EVA/BF and (b) e-EVA/WF.

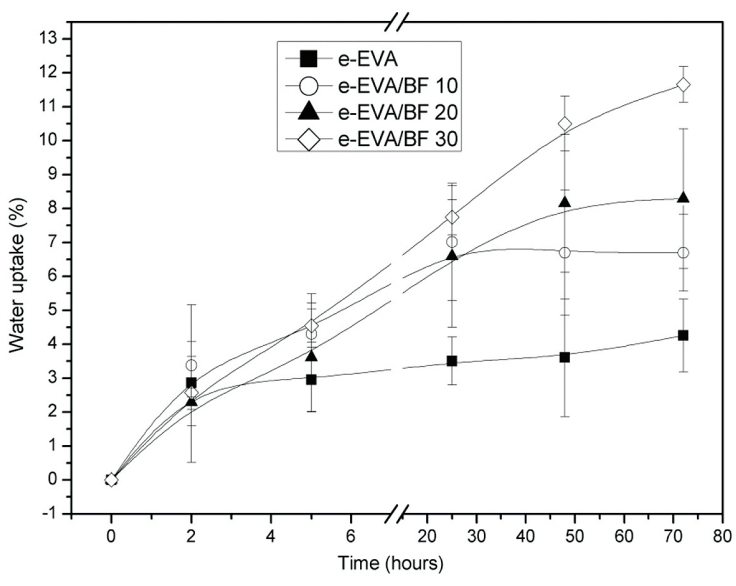

(a)

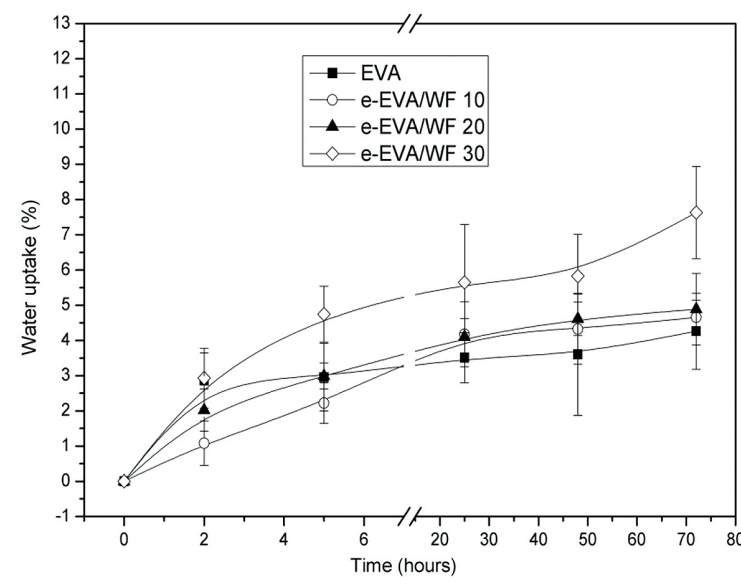

(b)

Figure 7. Water absorption of e-EVA and of expanded composites (a) produced with BF and (b) produced withWF. 


\section{Conclusions}

The following conclusions can be drawn from the results of the present study:

- The use of BF and WF in EVA polymeric expanded composites generally produces heterogeneous cells and a tendency towards a larger number of cells that are smaller in size with increasing filler content since the fillers acts as nucleating agents during expansion.

- The mechanical properties of tear strength, compression and hardness are strongly dependent on cellular density, fiber content and density of the expanded composites. MFI tends to decrease with increasing filler content, with a more pronounced

\section{References}

1. Barreto ACH, Costa MM, Sombra ASB, Rosa DS, Nascimento RF, Mazzetto SE, et al. Chemically modified banana fiber: structure, dielectrical properties and biodegradability. Journal of Polymer Environment. 2010; 18(4):523-531. http://dx.doi. org/10.1007/s10924-010-0216-X.

2. Guo G, Rizvi M, Park CB and Lin WSJ. Critical processing temperature in the manufacture of fine-celled plastic/woodfiber composite foams. Journal of Applied Polymer Science. 2004; 91(1):621-629. http://dx.doi.org/10.1002/app.13193.

3. Jandas PJ, Mohanty S, Nayak SK and Srivastava H. Effect of surface treatments of banana fiber on mechanical, thermal, and biodegradability properties of PLA/banana fiber biocomposites. Polymer Composites. 2011; 32(11):1689-1700. http://dx.doi.org/10.1002/pc.21165.

4. Venkateshwaram $\mathrm{N}$ and Elayaperumal AJ. Banana fiber reinforced polymer composites - a review. Journal of Reinforced Plastics and Composites. 2010; 23(15):2387-2396. http://dx.doi.org/10.1177/0731684409360578.

5. Zhang H, Rizvi GM and Park CB. Development of an extrusion system for producing fine-celled HDPE/wood-fiber composite foams using $\mathrm{CO} 2$ as a blowing agent. Advances in Polymer Technology. 2004; 23(4):263-276. http://dx.doi.org/10.1002/ adv.20016.

6. Rodrigue D, Souici S and Twite-Kabamba ET. Effect of wood powder on polymer foam nucleation. Journal of Vinyl \& Additive Technology. 2006; 12(1):19-24. http://dx.doi. org/10.1002/vnl.20062.

7. Bledzki A and Faruk O. Injection moulded microcellular wood fibre-polypropylene composites. Composites. Part A, Applied Science and Manufacturing. 2006; 37(9):1358-1367. http:// dx.doi.org/10.1016/j.compositesa.2005.08.010.

8. Rizvi GM, Matuana LM and Park CB. Foaming of PS/wood fiber composites using moisture as a blowing agent. Polymer Engineering and Science. 2000; 40(10):2124-2132. http:// dx.doi.org/10.1002/pen.11345.

9. Rizvi GM, Pop-Iliev R and Park CB. A novel system design for continuous processing of plastic/wood-fiber composite foams with improved cell morphology. Journal of Cellular Plastics. 2002; 38(5):367-383. http://dx.doi.org/10.1177/002 $1955 X 02038005786$

10. Doroudiani S and Kortschot MT. Expanded wood fiber polystyrene composites: processing-structure-mechanical properties relationships. Journal of Thermoplastic Composite Materials. 2004; 17(1):13-30. http://dx.doi. org/10.1177/0892705704035405. decrease observed for the composites produced with BF.

- Thermal analysis very clearly indicates an initial mass loss event in the natural fibers for the WF composite. This initial mass loss event is related to moisture in the sample and/or volatilization of extractives. The expanded composites using either type of fiber exhibit thermal properties that are intermediate between their constituent materials.

- The expanded composites tended to exhibit higher water absorption with increasing fiber content, with this tendency being most evident in the e-EVA/BF samples.

11. Eaves D, editor. Handbook of polymer foams. Shrewsbury: Rapra Technology; 2004. Chapter 1, p. 1-8.

12. Catto AL, Stefani BV, Ribeiro VF and Santana RMC. Influence of coupling agent in compatibility of post-consumer HDPE in thermoplastic composites reinforced with eucalyptus fiber. Materials Research. 2014; 17:203-209. http://dx.doi. org/10.1590/S1516-14392014005000036.

13. Poletto M, Dettenborn J, Zeni M and Zattera AJ. Characterization of composites based on expanded polystyrene wastes and wood flour. Waste Management (New York, N.Y.). 2011; 31(4):779784. http://dx.doi.org/10.1016/j.wasman.2010.10.027. PMid:21172732

14. Kim H, Lee B, Choi S, Kim S and Kim H. The effect of types of maleic anhydride-grafted polypropylene (MAPP) on the interfacial adhesion properties of bio-flour-filled polypropylene composites. Composites. Part A, Applied Science and Manufacturing. 2007; 38(6):1473-1482. http:// dx.doi.org/10.1016/j.compositesa.2007.01.004.

15. American Society for Testing and Materials - ASTM. D1622/ D1622M-14: Standard test method for apparent density of rigid cellular plastics. West Conshohocken; 2014. http://dx.doi. org/10.1520/D1622_D1622M-14.

16. Petchwattana $\mathrm{N}$ and Covavisaruch $\mathrm{S}$. Influences of particle sizes and contents of chemical blowing agents on foaming wood plastic composites prepared from poly(vinyl chloride) and rice hull. Materials \& Design. 2011; 32(5):2844-2850. http://dx.doi.org/10.1016/j.matdes.2010.12.044.

17. Li Q and Matuana LM. Foam extrusion of high density polyethylene/wood-flour composites using chemical foaming agents. Journal of Applied Polymer Science. 2003; 88(14):31393150. http://dx.doi.org/10.1002/app.12003.

18. American Society for Testing and Materials - ASTM. D624-00(2012): Standard test method for tear strength of conventional vulcanized rubber and thermoplastic elastomers. West Conshohocken; 2012. http://dx.doi.org/10.1520/D062400R12.

19. American Society for Testing and Materials - ASTM. D2240-05(2010): Standard test method for rubber propertydurometer hardness. West Conshohocken; 2010. http://dx.doi. org/10.1520/D2240-05R10.

20. American Society for Testing and Materials - ASTM. D162110: Standard test method for compressive properties of rigid cellular plastics. West Conshohocken; 2010. http://dx.doi. org/10.1520/D1621-10.

21. American Society for Testing and Materials - ASTM. D123813: Standard test method for melt flow rates of thermoplastics 
by extrusion plastometer. West Conshohocken; 2013. http:// dx.doi.org/10.1520/D1238.

22. Zimmermann MVG, Brambilla VC, Brandalise RN and Zattera AJ. Observations of the effects of different chemical blowing agents on the degradation of poly(lactic acid) foams in simulated soil. Materials Research. 2013; 16(6):1266-1273. http://dx.doi.org/10.1590/S1516-14392013005000133.

23. Rodriguez-Perez MAR, Simoes RD, Constantino CJL and de Saja JA. Structure and physical properties of EVA/starch precursor materials for foaming applications. Journal of Applied Polymer Science. 2011; 121(4):2324-2330. http:// dx.doi.org/10.1002/app.33946.

24. Guo G, Lee YH, Rizvi GM and Park CB. Influence of wood fiber size on extrusion foaming of wood fiber/HDPE composites. Journal of Applied Polymer Science. 2008; 107(6):3505-3511. http://dx.doi.org/10.1002/app.27467.

25. Caraschi JC and Leão AL. Woodflour as reinforcement of polypropylene. Materials Research. 2002; 5(4):405-409. http:// dx.doi.org/10.1590/S1516-14392002000400003.
26. Kim H-S, Kim S, Kim H-J and Yang H-S. Thermal properties of bio-flour-filled polyolefin composites with different compatibilizing agent type and content. Thermochimica Acta. 2006; 451(1-2):181-188. http://dx.doi.org/10.1016/j. tca.2006.09.013.

27. Poletto M, Zattera AJ, Forte MMC and Santana RMC. Thermal decomposition of wood: influence of wood components and cellulose crystallite size. Bioresource Technology. 2012; 109:148-153. http://dx.doi.org/10.1016/j.biortech.2011.11.122. PMid:22306076

28. Annie Paul S, Boudenne A, Ibos L and Candau Y, Joseph K and Thomas S. Effect of fiber loading and chemical treatments on thermophysical properties of banana fiber/polypropylene commingled composite materials. Composites. Part A, Applied Science and Manufacturing. 2008; 39(9):1582-1588. http:// dx.doi.org/10.1016/j.compositesa.2008.06.004.

29. Ichazo MN, Albano C, González J, Perera MV and Candal MV. Polypropylene/wood flour composites: treatments and properties. Composite Structures. 2001; 54(2-3):207-214. http://dx.doi.org/10.1016/S0263-8223(01)00089-7. 